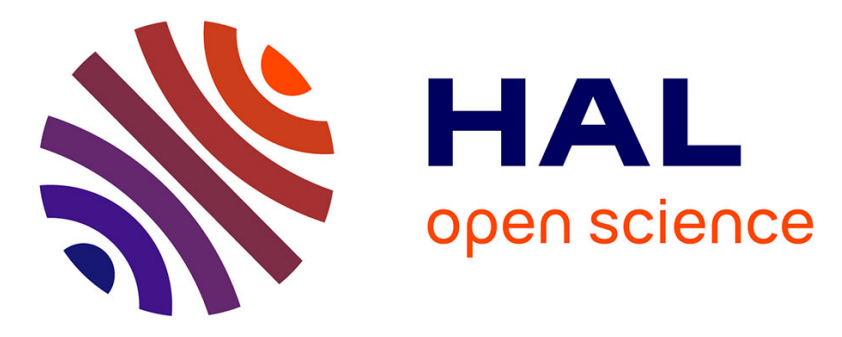

\title{
A Framework for Data-Driven Public Service Co-production
}

Maarja Toots, Keegan Mcbride, Tarmo Kalvet, Robert Krimmer, Efthimios

Tambouris, Eleni Panopoulou, Evangelos Kalampokis, Konstantinos Tarabanis

\section{- To cite this version:}

Maarja Toots, Keegan Mcbride, Tarmo Kalvet, Robert Krimmer, Efthimios Tambouris, et al.. A Framework for Data-Driven Public Service Co-production. 16th International Conference on Electronic Government (EGOV), Sep 2017, St. Petersburg, Russia. pp.264-275, 10.1007/978-3-31964677-0_22 . hal-01702980

\section{HAL Id: hal-01702980 \\ https://hal.inria.fr/hal-01702980}

Submitted on 7 Feb 2018

HAL is a multi-disciplinary open access archive for the deposit and dissemination of scientific research documents, whether they are published or not. The documents may come from teaching and research institutions in France or abroad, or from public or private research centers.
L'archive ouverte pluridisciplinaire HAL, est destinée au dépôt et à la diffusion de documents scientifiques de niveau recherche, publiés ou non, émanant des établissements d'enseignement et de recherche français ou étrangers, des laboratoires publics ou privés. 


\title{
A Framework for Data-Driven Public Service Co-Production
}

\author{
Maarja Toots ${ }^{1}$, Keegan McBride ${ }^{1}$, Tarmo Kalvet ${ }^{1}$, Robert Krimmer ${ }^{1}$, Efthimios Tam- \\ bouris $^{2}$, Eleni Panopoulou ${ }^{2}$, Evangelos Kalampokis ${ }^{2}$, Konstantinos Tarabanis ${ }^{2}$ \\ ${ }^{1}$ Tallinn University of Technology, Tallinn, Estonia \\ maarja.toots|keegan.mcbride | tarmo. kalvet | robert.krimmerettu.ee \\ ${ }^{2}$ University of Macedonia, Thessaloniki, Greece \\ tambourisenom.gr
}

\begin{abstract}
Governments are creating and maintaining increasing amounts of data, and, recently, releasing data as open government data. As the amount of data available increases, so to should the exploitation of this data. However, this potential currently seems to be unexploited. Since exploiting open government data has the potential to create new public value, the absence of this exploitation is something that should be explored. It is therefore timely to investigate how the potential of existing datasets could be unleashed to provide services that create public value. For this purpose, we conducted a literature study and an empirical survey of the relevant drivers, barriers and gaps. Based on the results, we propose a framework that addresses some of the key challenges and puts forward an agile co-production process to support effective data-driven service creation. The proposed framework incorporates elements from agile development, lean startups, co-creation, and open government data literature and aims to increase our understanding on how open government data may be able to drive public service cocreation.
\end{abstract}

Keywords: Open data, Public services, Co-production, Co-creation, Agile development.

\section{$1 \quad$ Introduction}

Currently, there is a trend among governments to try to become more 'open'. One aspect of an open government is opening up government data [1], [2], [3]. However, it is known that simply providing open government data (OGD) does not automatically result in significant value for society [1]. The literature often cites the many potential benefits of OGD [4], [1], [5], [6], however, the point still holds that these benefits will not be realized unless data is actually used. Thus, a concrete understanding of barriers that prevent OGD from being utilized to produce public value is essential. As a continuance to this, a framework is needed to guide the use of OGD in an effective and efficient manner producing as much public value as possible. 
This paper aims to address the current gap in literature related to the usage of OGD for the co-production of new public services. To this end, the paper proposes a conceptual framework based on current knowledge from literature, as well as an empirical survey conducted within six EU countries, and aims to help make sense of the ways that OGD may be turned into services that create public value. The survey was carried out with the aim of eliciting responses on the core needs and expectations for service co-production; the survey also sought understanding of how the co-production of public services may be applied to the production of data-driven public services. Once the survey results had been received, analyzed and interpreted, work on the proposed framework began.

The proposed framework takes a unique approach in three main areas: Firstly, we suggest a change in understanding from the traditional definition of a public service as something produced and provided by the government to society. Secondly, we argue that OGD-driven service creation is, by its nature, a process of co-production, conducive to collaboration between different kinds of stakeholders such as public administrations, citizens and businesses. Thirdly, the framework proposes to consider the use of agile development practices in the creation of data-driven services.

The paper is structured as follows. Section 2 presents background information on key elements of OGD-driven public service delivery based on a review of relevant literature; this is then followed by a brief overview of the empirical results. Section 3 outlines the proposed framework for data-driven public service co-production. This is followed by Section 4, which provides some reflections on the framework. Lastly, Section 5 gives conclusions and suggestions for further research.

\section{Background}

The initial starting point and goal for this research was to define and understand OGD. To this end, a literature search was conducted for articles that contained the phrases "open data" or "open government data" in the e-government reference library as well as Google Scholar. Though there are many different ways to interpret OGD, for this paper the definition proposed by [1] is used: "non-privacy restricted and non-confidential data which is produced with public money and is made available without any restrictions on its usage or distribution". To further expand on this, OGD should also be machine readable, discoverable, and usable by end users (see, for example, [7] and [8]).

There is rich evidence stating that OGD has the potential to drive innovation [1], [9], [10], [36], it allows for increased levels of transparency [1], helps drive the creation or implementation of new public services [1], [4], [9], [36] and helps empower citizens and communities [1]. However, there are also barriers that seem to inhibit these benefits from manifesting. Some of the main barriers in the literature include issues with data quality [1], [2], [3], [36], lack of government willpower [1], [2], [3], [11], [26], confidentiality issues [5], [10], [12], and absence of understanding of OGD [1], [3], [11], [13], [36]. It is clear that OGD may be used to drive innovation and change how public 
services are created. This in turn could, potentially, empower citizens by providing easier ways to interact with government data and play a role in the public service creation process.

An important use of OGD is in its potential contribution to public services, though this is another area where future research is needed. As Janssen et al. (2012) suggest "little is known about the conversion of public data into services of public value. Hence, we strongly suggest further research in this area" [1]. A recent paper by Foulonneau et al. (2014) finds that there are three main roles which data plays in a new service: "the service is based on data, the service uses data as a resource, and the service is validated or enriched with data but the data is not directly used or is not directly visible in the service." [4]. They also find that OGD is currently underutilized, and applications that create public value only utilize a small number of datasets. Charalabidis et al. (2016) find that OGD can allow services to be co-created by non-typical service producers which results in the building of new and innovative applications [12]. Thus, OGD may be used for the co-creation of public services. The process of using OGD in public service co-production may be summarized as follows: governments make open data available, potentially anyone can use this data to create a new service, and it is this interaction that allows a service to be 'co-produced'.

Co-production was initially defined by Elinor Ostrom in 1972, and it can be understood as "the process through which inputs used to provide a good or service are contributed by individuals who are not 'in' the same organization" [14]. Since this initial definition, co-production has gained increasing attention in the academic literature. What is, generally, agreed upon is that the value of a public service is very much determined by not just the provider of the service but also by the interaction between the consumer of the service and the provider [14], [15], [16]. Since OGD allows many new interactions to take place between government and society, it follows that these interactions have the potential to lead to 'co-produced data-driven public service'.

When looking at the current literature on co-production, two different categorization schemes can be extracted. The first categorization takes a more hierarchical approach where co-production is categorized based on different levels of co-production within a service (for examples, see: [2], [17], [16], [18]). In contrast to the first categorization, the second defines co-production differently depending on what stage it occurs in during the creation or implementation of a new public service (for examples, see: [15], [19], [20]). What can be seen from this is that the idea of 'co-production' is still heavily debated, but it does provide an important way to look at and understand how public services are designed, created, implemented, maintained, and used.

As the literature study was ongoing, the survey was also started. The goal of this survey was to collect empirical data on the practical challenges that have been met by different actors in using OGD for the co-creation of new services. The survey elicited responses from experts and practitioners and was conducted in $6 \mathrm{EU}$ countries (Belgium, Estonia, Greece, Ireland, Lithuania and the UK)1. In addition to their differences in terms of the political system and public administration tradition, these countries also

1 The study was conducted as part of the OpenGovIntelligence project, a research and innovation action funded from the EU's Horizon 2020 program under grant agreement no 693849. 
differ for their government data exchange systems and level of open data maturity, involving early adopters, such as the UK, as well as laggards, such as Estonia or Lithuania. The survey yielded 63 responses from public administration, business, civil society and research actors and revealed a number of barriers and drivers that are seen to affect OGD-driven service co-production (a more detailed overview of the study has been published in [36]). Some of the key barriers that came out of the survey include lack of availability of open data, little awareness of the benefits and uses of OGD, lack of feedback loops between public service providers and users, missing data-related skills in the public sector, lack of collaboration between stakeholders, low political priority and organizational resistance in the public sector, etc. The drivers seem to be polar opposites of the barriers, for example, lack of funding is a barrier whereas access to funding or external funding acts as a driver. Other examples are seen as well, for example, low political priority or lack of awareness of OGD benefits may be a barrier, but a clear demand from citizens and demonstrating tangible benefits can be used to counteract this.

From the literature it does appear that OGD may be used to help drive public service co-creation, but from the survey it is also clear that there are many barriers that stand in the way. It seems that a new approach is needed in order to help overcome these barriers so that OGD-driven public service co-creation may begin to thrive. This new approach should allow other stakeholders to take the driver's seat in exploiting OGD to create services and generate public value. In Section 3, one possible solution - a coproduction framework for OGD-driven public service co-creation - is presented.

\section{Proposal for a Co-production Framework for Data-Driven Public Services}

\subsection{The concept of open government data-driven public service co-production}

In order to understand the building blocks of OGD-enabled public service creation, it is useful to look at services as open systems that are inseparable of the environment in which they operate. According to an emerging view in service management research, the production of a service is a "product of a complex series of, often iterative interactions, between the service user, the service organization and its managers and staff, the physical environment of the service, other organizations and staff supporting the service process, and the broader societal locus of the service" [21]. This view is supported by the current trends in public sector innovation and e-government literature, where the importance of context is increasingly emphasized (see, for example, [22],[23]). This framework for data-driven public services, therefore, looks at OGD as part of a broader service ecosystem that consists of the technological infrastructures needed for the publication and exploitation of OGD, interactions between stakeholders, and the social, organizational, cultural, legal and political environment where services are created.

Traditionally, public services have been understood as something designed and delivered by public administrators to the public. In this traditional system, public administrators act as "brokers" between society and the political system, attempting to feed 
society's needs to the relevant political bodies who, in turn, produce public services to meet these needs [24]. This understanding is beginning to erode both in the political realm (e.g. [25]) and research (e.g. [26]; [27]), being supplemented or even replaced by a co-production-oriented approach where governments are encouraged to open their data and service creation process to non-governmental stakeholders. However, there are also more radical visions; the European Commission [28] proposes an approach according to which public services are any services which are offered to the general public with the purpose of developing public value, regardless of the role that the public sector plays in the process. In this view, the creation and provision of public services is no longer a monopoly of the public sector. Instead, any public or private actor may take the lead in developing a new service that creates public value, and any actor can participate in the co-production of this service. This is believed to lead to more user-friendly, proactive and personalized services, increased trust in administrations, and empowerment of citizens [28].

The concept of OGD naturally fits this scenario. When government data is made accessible and reusable by the public, it is possible for any interested party to use this data to offer new data-driven public services. If a problem or need is perceived, citizens and businesses are able to easily take the initiative and build their own services based on OGD, engaging other stakeholders in the process of co-production as needed. In the context of such services, data may have different roles, as explained by Foulonneau et al. [4]. Data may also come from various sources and in various volumes - from large open government datasets to data provided by individual users. In short, it may be said that any service that provides public value by using or exploiting data may be considered a data-driven public service.

The adoption of a collaborative model of data-driven service creation entails the need to redefine the traditional roles of public and private actors in the process. The concept of New Public Service [29] provides useful guidance in this respect. This approach places citizens at the center, emphasizing serving over steering, the importance of public interest, a view of service users as citizens not customers, and the value of people and partnerships. As suggested by Hartley et al. [22], collaborative innovation requires a thorough rethinking of the roles of all stakeholders: politicians need to redefine their role from "political sovereigns who have all the power and responsibility" to ones setting the agenda through dialogue with relevant actors; public managers should redefine their role from experts-technocrats to "meta-governors" who orchestrate collaborative arenas; private companies and voluntary organizations need to become "responsible partners in the production of innovative solutions for public value" rather than promoters of their own interests; and citizens should assume the role of "co-creators and co-producers" rather than "clients, customers, or regulatees". Therefore, a coproduced data-driven public service not only needs data to be provided and used, but also stakeholders need to assume new roles in the creation of public value.

\subsection{The process of open data-driven public service co-production}

Co-production of data-driven services. Pollitt and colleagues (2006) divide the service co-production process into four phases: co-planning, co-design, co-delivery, and 
co-evaluation [20]. It has been found vital to sustain close collaboration with users and stakeholders throughout this cycle to ensure the quality of services [30]. In the context of data-driven services, this collaboration involves the provision and use of data in these different phases. While public organizations have the key role in publishing government datasets as open data, citizens can also contribute their data in different ways, depending on their level of interest and skills. For instance, any citizen may notify the government about problems such as potholes or graffiti using smartphones or web apps. Such crowdsourcing models are used in the well-known services of FixMyStreet and StreetBump2. At the same time, citizens with more advanced skills can engage in mining and analyzing OGD to explore patterns or discover problems [31]. As an example, residents of an area could scan data provided in waste collection plans and report problems to improve the collection schedule or locations [32]. Citizens may contribute to service design and partake in the development of data mashups and apps to address needs that have been discovered [31]. Similarly, citizens may be co-implementers of services by contributing user data (e.g. through sensors) or giving feedback for monitoring and evaluation [32]. Although citizens and other stakeholders may be valuable data providers, the provision of OGD remains a key driver in this process due to the volume and value of government datasets.

Agile development and continuous improvement. In order for OGD-driven co-production to be effective, we suggest to move away from the traditional waterfall-like service development model (see: fig.1) and learn from the agile approach. The agile approach has become the norm in private sector ICT projects, but is still relatively new to the public sector. In the traditional waterfall model there is a linear approach to development where the project requirements are all outlined at the beginning and the development happens late into the project design cycle. In this traditional model, the public administrators are steering and controlling the whole process with citizen input being occasionally, but not necessarily, sought. In the traditional model, a service is slow to create, not easily adaptable, and may not have many adequate ways to receive feedback from the service user.

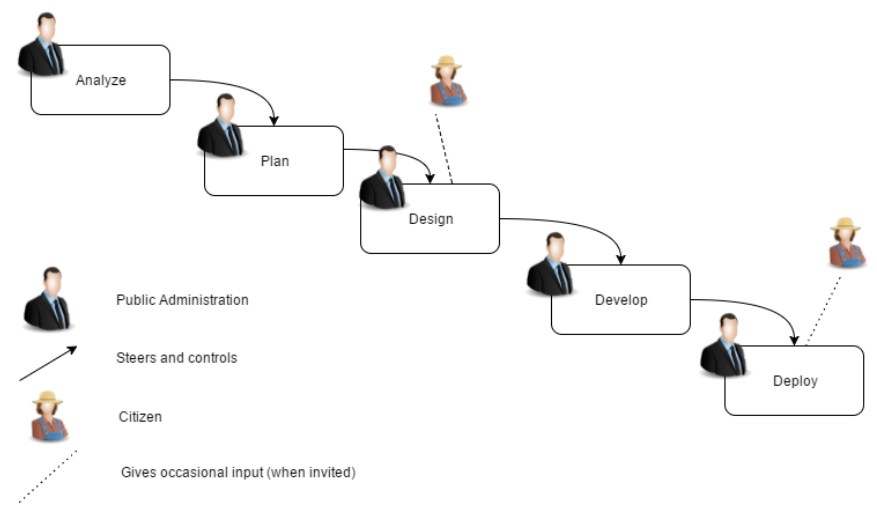

Fig. 1. Traditional model of public service creation

2 See www.fixmystreet.com; www.streetbump.org 
Agile development focuses on being able to adapt quickly to changes by following an 'agile' approach that is based on multiple sprints made up of four main stages: plan, build, test, release [33], [34]. One concept within agile development is the idea of the Minimum Viable Product (MVP). The goal of an MVP is to develop a product or service, at its most basic and functional form, and release it as quickly as possible. Once the MVP has been released, it allows for fast feedback from service users. Ultimately, this allows for rapidly generated understanding of service use, which may then be used to adapt and change the service; this also leads to a cheaper service that is more in tune with the users' wants and needs.

Society's feedback. Feedback from users and stakeholders is a core aspect of the data-driven public service. This feedback comes in many forms, but ultimately has one goal: improving the offered service. Feedback may be received in relation to the data that is being offered, the exploitation methods, and the new services themselves. Many different methods could be utilized for obtaining feedback. Some of the most likely feedback forms are 1) feedback mechanisms for user-provided data built directly into the public service, 2) social media, and 3) user workshops. A successful process for feeding feedback into the new public service will likely utilize some combination of these proposed feedback mechanisms.

User-provided data. When creating a new public service, it is important to make sure that the proper feedback mechanisms are in place. For a data-driven public service, users should be able to either upload their own data, suggest changes to datasets, or be able to participate directly in data creation for a service (this could be done via a phone app, sensors, etc.). The goal is to make sure that service users have some direct role in the creation/design of a service, and that they are able to provide continuous feedback into the service that is listened to and utilized.

Social media. Social media allows feedback to be received almost instantaneously from a large amount of users. One way to use social media, which stands out in terms of effectiveness, is data mining, such as opinion mining or sentiment analysis. When there is an increase in usage of a newly created service, tweets, Facebook posts, etc. could be followed and notifications could be received any time a post related to the new public service is created. These posts could be automatically understood as positive or negative or neutral, from there further investigation could provide insight into what part of a service was well executed, and what part should be changed on future implementations.

User workshops. One of the best ways to include end-users in service design is through the organization of user workshops; user workshops usually combine individual ideation with group discussion. These workshops should be repeated throughout the lifecycle of the new data-driven service. In terms of outcomes, user workshops should be able to produce a list of issues with the new service, a list of potential solutions, basic thoughts on the usability and functionality of the service, user stories, a list of user personas of individuals who could use the service, and any other information that may come out of the workshop organically. This information will allow government and citizens to work together and get a better understanding of the content, functions and goals of the service. 
Towards agile co-production of open data-driven services. When examining the aforementioned definitions, it is important to pick up the commonalities between these different ideas: focus on the service user, be agile, develop quickly, listen to the service user, and be able to adapt quickly to changing needs. The service innovation process can be summarized with the following points:

- The government and citizens should be partners at all stages from ideation to creation to implementation of the new data-driven public service.

- There should be an initial release of the public service at an early stage, or an 'MVP' of the public service, which allows the cycle to be started as quickly as possible.

- The public service should be able to respond to user feedback from the initial launch.

- User input should be sought and utilized at all stages of the public service creation.

\section{Discussion}

In public service provision, a shift from a public administrator-centric view towards wider collaboration and interaction made possible by technological advances is observed. We present a framework (Fig. 2), for data-driven public services that includes a wider view of stakeholders and is built around two key elements - co-production and agile development.

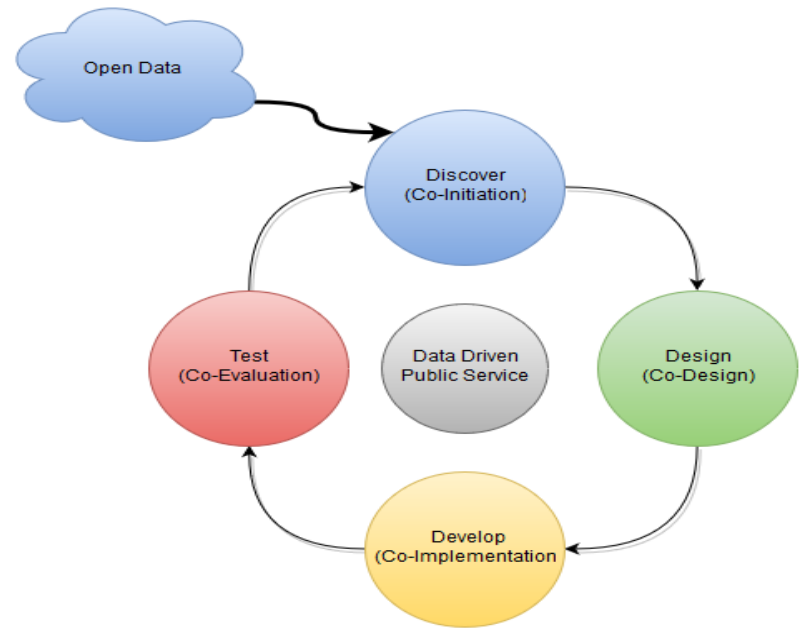

Fig. 2. Agile co-production framework for data-driven public services

Addressing these elements properly may help to drive innovation in the public sector, private sector as well as in the non-governmental sector, increase transparency, empower citizens and other stakeholder groups as well as achieve more effective and efficient public service delivery, and thus enhance public value.

The framework places a large focus on agile development and co-production/cocreation. It is believed that the focus on these attributes may allow for barriers that emerged from the literature and the survey to be overcome. The co-production element 
may help to overcome several data and technology related key barriers, such as limited supply and fragmentation of OGD (as other stakeholders could complement public OGD with their own data) and the overall development of data infrastructures, standards as well as specific tools, applications and demos that facilitate service creation. The agile development focus would help to keep the cost down for developing OGD driven applications while also allowing for more opportunities for co-creation of the service to emerge. This would, potentially, initiate a virtuous circle - if better data infrastructures and services are made available, new services could be built on the basis of those. Also, they potentially fuel the demand for additional services.

Agile development and continuous improvement are principles widely used in private sector ICT projects; it seems that they may also be incorporated in public service creation to help realize the future of public service delivery. The implementation of this framework would enable a new understanding of the costs and benefits of OGD services more promptly, open opportunities for further synergies (as contributions from other stakeholders can be incorporated immediately into public service), and make the delivery more effective and efficient, potentially increasing the legitimacy of public sector and lowering resistance to OGD as well. As the performed expert survey revealed that stakeholders' attitudes currently constitute the biggest barrier as OGD generally lacks tangible benefits, this last point on lowering resistance seems to be important.

The use of co-production and agile development surely would not help directly overcome other important barriers, such as possible legal and political barriers. However, by improving the overall understanding and demonstrating the value of OGD-driven services, it could help put the topic higher on the political agenda and lower fears.

\section{Conclusions}

It has become clear that there is a discrepancy between the hopes attached to OGD as an enabler of new services, and the reality where the creation of these services is facing a number of challenges. Studying how these challenges could be overcome, we find that any viable solution needs to tackle several issues at once: there needs to be a supply of OGD, but we also need a fundamental rethinking of the concept of public services, the service creation process, and the roles of different actors in the process.

The framework presented in this paper aims to make an initial contribution towards the understanding of how OGD may be used to co-create new service that produce public value. Furthermore, we argue that the traditional government-driven top-down waterfall-like method of public service production no longer fits the increasing demand for needs-based, customized and responsive services. The framework puts forth an innovative process, based on the ideas of co-production and agile development, in the hope that it may lead to the creation of new services in a more efficient and collaborative way.

The framework views service development as part of an ecosystem that consists of different actors, processes, and drivers and barriers related to the broader environment. While we strongly believe in the value of a systemic approach, we also acknowledge 
the limitations of our current understanding of the obstacles that may affect the implementation of this framework in practice. As the next step, it is therefore vital to test this on real-life cases in different contexts, so that further development and refinement of the framework may take place as new lessons are learned.

Acknowledgements. This work was supported by the European Commission (OpenGovIntelligence H2020 grant 693849), Estonian Research Council (PUT773, PUT1361) and Tallinn University of Technology Project B42.

\section{References}

1. M. Janssen, Y. Charalabidis, and A. Zuiderwijk, "Benefits, Adoption Barriers and Myths of Open Data and Open Government," Information Systems Management (ISM), vol. 29, no. 4, pp. 258-268, 2012.

2. S. Martin, M. Foulonneau, S. Turki, and M. Ihadjadene, "Open Data: Barriers, Risks and Opportunities," in 13th European Conference on eGovernment (ECEG 2013), Como, Italy, pp. 301-309, 2013.

3. A. Zuiderwijk, M. Janssen, S. Choenni, R. Meijer, and R. S. Alibaks, "Socio-technical Impediments of Open Data," Electronic Journal of Electronic Government, vol. 10, no. 2, pp. 156-172, 2012.

4. M. Foulonneau, S. Turki, G. Vidou, and S. Martin, "Open data in service design," Electronic Journal of e-Government, vol. 12, no. 2, pp. 99-107, 2014.

5. K. Janssen, "The influence of the PSI directive on open government data: An overview of recent developments," Government Information Quarterly, vol. 28, no. 4, pp. 446-456, 2011.

6. "Rebooting Public Service Delivery - How can Open Government Data help drive innovation?" OECD, 2016. Available: http://www.oecd.org/gov/digital-government/rebootingpublic-service-delivery.htm

7. OMB, Memorandum M-13-13, Open Data Policy-Managing Information as an Asset, 2013. Available: https://project-open-data.cio.gov/policy-memo/

8. Open Definition 2.1. Available: http://opendefinition.org/od/2.1/en/

9. C. M. L. Chan, "From Open Data to Open Innovation Strategies: Creating E-Services Using Open Government Data," in Proceedings of the 46th Hawaii International Conference on System Sciences (HICSS-46), Wailea, HI, USA, 2013, pp. 1890-1899, IEEE Computer Society.

10. G. Juell-Skielse, A. Hjalmarsson, P. Johannesson, and D. Rudmark, "Is the Public Motivated to Engage in Open Data Innovation?," in Electronic Government: Proceedings of the 13th IFIP WG 8.5 International Conference, EGOV 2014, Dublin, Ireland, 2014, vol. 8653, pp. 277-288.

11. F. Gonzalez-Zapata and R. Heeks, "The multiple meanings of open government data: Understanding different stakeholders and their perspectives," Government Information Quarterly, vol. 32, no. 4, pp. 441-452, 2015.

12. Y. Charalabidis, C. Alexopoulos, V. Diamantopoulou, and A. Androutsopoulou, "An Open Data and Open Services Repository for Supporting Citizen-Driven Application Development for Governance," in 49th Hawaii International Conference on System Sciences (HICSS 2016), Kauai, HI, USA, 2016, pp. 2596-2604, Kauai, HI, USA: IEEE. 
13. G. Misuraca and G. Viscusi, "Is Open Data Enough? E-Governance Challenges for Open Government," International Journal of Electronic Government Research, vol. 10, no. 1, pp. 18-34, 2014.

14. E. Ostrom, "Crossing the Great Divide: Synergy, and Development," World Development, vol. 24, no. 6, pp. 1073-1087, 1996.

15. S. P. Osborne, Z. Radnor, and K. Strokosch, "Co-Production and the Co-Creation of Value in Public Services: A suitable case for treatment?" Public Management Review, vol. 18, no. 5, pp. 639-653, 2016.

16. S. P. Osborne and K. Strokosch, "It takes Two to Tango? Understanding the Co-production of Public Services by Integrating the Services Management and Public Administration Perspectives," British Journal of Management, vol. 24, pp. S31-S47, 2013.

17. E. Bracci, M. Fugini, and M. Sicilia, "Co-production of Public Services: Meaning and Motivations," in Co-production in the Public Sector, vol. 1, M. Fugini, E. Bracci, and M. Sicilia, Eds. (PoliMI SpringerBriefs: Springer International Publishing, 2016, pp. 1-2.

18. V. Pestoff, "Co-production and Third Sector Social Services in Europe," in New Public Governance, the Third Sector and Co-production, B. Verschuere, T. Brandsen, and V. Pestoff, Eds. New York: Routledge, 2012.

19. V. Pestoff, "Co-production as social and governance innovation in public services," Polittyka Spoleczna vol. 11, no. 1, pp. 2-8, 2015.

20. C. Pollitt, G. Bouckaert, and E. Loeffler, "Making Quality Sustainable: Co-design, Codecide, Co-produce, Co-evaluate," presented at the 4QC Conference, 2006.

21. Z. Radnor, S. P. Osborne, T. Kinder, and J. Mutton, "Operationalizing Co-Production in Public Services Delivery: The contribution of service blueprinting," Public Management Review, vol. 16, no. 3, pp. 402-423, 2014.

22. J. Hartley, E. Sørensen, and J. Torfing, "Collaborative Innovation: A Viable Alternative to Market Competition and Organizational Entrepreneurship," Public Administration Review, vol. 73, no. 6, pp. 821-830, 2013.

23. Y. K. Dwivedi et al., "Research on information systems failures and successes: status update and future directions," Information Systems Frontiers, vol. 17, no. 1, pp. 143-157, 2015.

24. V. Peristeras and K. Tarabanis, "The Governance Architecture Framework and Models," in Advances in Government Enterprise Architecture, P. Saha, Ed. Hershey, PA: IGI Global Information Science Reference, 2008.

25. European Commission, EU eGovernment Action Plan 2016-2020: Accelerating the digital transformation of government, 2016. Available: http://ec.europa.eu/newsroom/dae/document.cfm?doc_id=15268

26. T. Bovaird and E. Loeffler, "From Engagement to Co-production: The Contribution of Users and Communities to Outcomes and Public Value," International Journal of Voluntary and Nonprofit Organizations, vol. 23, no. 4, pp. 1119-1138, 2012.

27. G. Galasso, G. Farina, D. Osimo, F. Mureddu, T. Kalvet and P. Waller, "Analysis of the Value of New Generation of eGovernment Services and How Can the Public Sector Become an Agent of Innovation through ICT”, 2016.

28. "A vision for public services," European Commission. Directorate-General for Communications Networks, Content and Technology, 2013.

29. R. B. Denhardt and J. V. Denhardt, "The New Public Service: Serving Rather than Steering," Public Administration Review, vol. 60, no. 6, pp. 549-559, 2000.

30. "Together for Better Public Services: Partnering with Citizens and Civil Society," in "OECD Public Governance Reviews," OECD, 2011. 
31. S. Nambisan and P. Nambisan, "Engaging Citizens in Co-Creation in Public Services: Lessons Learned and Best Practices," in "Collaboration Across Boundaries Series," IBM Center for The Business of Government2013.

32. S. Scherer, M. Wimmer, and S. Strykowski, "Social government: A concept supporting communities in co-creation and co-production of public services," in dg.o '15, New York, USA, 2015, pp. 204-209: ACM.

33. K. Beck et al., Manifesto for agile software development, 2001. Available: http://agilemanifesto.org/

34. J. Highsmith and A. Cockburn, "Agile software development: The business of innovation," Computer, vol. 34, no. 9, pp. 120-127, 2001.

35. T. Kalvet, "Innovation: a factor explaining e-government success in Estonia," Electronic Government, an International Journal, vol. 9, no. 2, pp. 142-157, 2012.

36. M. Toots, K. McBride, T. Kalvet, R. Krimmer, "Open Data as Enabler of Public Service Co-creation: Exploring the Drivers and Barriers," in P. Parycek and N. Edelma, Eds, Proceedings of the 7th international conference for e-democracy and open government, Danube University Krems, Austria, 2017. pp. 102-112. 